\title{
On the morphology and potential application of polydimethylsiloxane-silica-titania composites
}

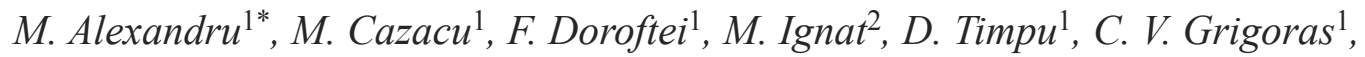 \\ B. C. Simionescu ${ }^{1,3}$ \\ 1'Petru Poni' Institute of Macromolecular Chemistry, Aleea Gr. Ghica Voda 41 A, 700487 Iasi, Romania \\ ${ }^{2}$ National Institute for Research and Development in Electrical Engineering ICPE-CA, Splaiul Unirii 313, 030138 \\ Bucharest, Romania \\ ${ }^{3}$ Department of Natural and Synthetic Polymers, 'Gh. Asachi’ Technical University of Iasi, 700050 Iasi, Romania
}

Received 29 July 2010; accepted in revised form 27 October 2010

\begin{abstract}
Polydimethylsiloxane- $\alpha, \omega$-diol was used as matrix for the preparation of polysiloxane- $\mathrm{SiO}_{2}-\mathrm{TiO}_{2}$ composites through in situ incorporation of silica and titania using a solvent-free sol-gel procedure. For this purpose, oxide precursors tetraethyl-orthosilicate and tetrabutyl-orthotitanate, and a proper condensation catalyst, viz. dibuthyltin dilaurate, were added in pre-established amounts to the polymer. The hydrolysis and condensation reactions take place under mild conditions, with the formation of silicon and titanium oxide networks and polymer crosslinking. The effect of $\mathrm{SiO}_{2}$ and $\mathrm{TiO}_{2}$ mass ratio on the morphology of the composites was investigated by scanning electron microscopy (SEM) and X-rays diffraction (XRD), and interpreted in correlation with differential scanning calorimetry (DSC) and energy-dispersive X-ray spectroscopy (EDX) data. The film samples were tested as active elements in actuation devices.
\end{abstract}

Keywords: polymer composites, reinforcements, materials testing

\section{Introduction}

Silicones possess many excellent properties (thermal stability over a large temperature range, low surface tension, low dielectric constant, high hydrophobicity and a high degree of water-repellency, etc.). The condensed polysiloxanes have special mechanical properties compared to most organic polymers at moderate temperatures [1]. The extremely high mobility of the siloxane chain leads to a low glass-transition temperature [2], and this is why polydimethylsiloxanes remain fluid and silicone elastomers remain flexible at low temperatures [2]. In order to develop materials with useful properties, high molecular weights, chemical crosslinking and reinforcement are required.

The incorporation of different inorganic components into siloxane-based structures is carried out in order to improve the mechanical, thermal, electrical and optical properties and the dimensional stability or to obtain new properties derived from the hybrid nature of the material [3-5]. Therefore, due to their potential for large gains in mechanical and morphological properties, polymer/inorganic particle composites have received considerable interest. Silica, in the form of silica fume or aerogel with particle sizes in the nanometric range is the most preferred filler for silicones, although carbon black has been also used [6]. Other components can be added as well to achieve the desired properties. Thus, ferric oxide, titanium dioxide and organometallic compounds are added as heat stabilizers or pigments [7]. Titanium dioxide is one of the most important fillers used for obtaining composites designed for engineering applications [8]. Polymer- $\mathrm{TiO}_{2}$ com-

\footnotetext{
${ }^{*}$ Corresponding author, e-mail: amihaela@icmpp.ro
}

(c) BME-PT 
posites have been successfully prepared by using different polymer matrices - silicone elastomers [9], polyacrylates [10], poly(methyl methacrylate) [11], polyamide 6 [12], polyimides [13], polystyrene [14], polycarbonates [15], epoxies [16], unsaturated polyesters [17], and dental composites [18].

Titanium dioxide confers optical, photocatalytic and bactericide properties to the materials incorporating it. It has the advantage of a high chemical and thermal stability and non-toxicity [19]. Titania is transparent to visible light and possesses a high refractive index $(n=2.7)$. Optical silicones have excellent properties but their applications are limited due to the small value of the refractive index $(n \sim 1.5)$. The increase of their refractive index has a major impact in a range of applications, including optical devices for space environments and optical encapsulants [8]. Titanium dioxide has become a usual photocatalyst for both air and water purification [20]. Titania has a high dielectric constant $(\varepsilon \sim$ $89)$ being of real interest as an active filler in the modification of the dielectric properties of silicones as well as of other polymers [21,22].

$\mathrm{TiO}_{2}-\mathrm{SiO}_{2}$ composites have received much attention as raw materials in the production of low thermal expansion glasses, photonic crystals, dispersed phases of electrorheological fluids, catalysts for the removal of sulfur from fuel oil, ethylene terephthalate polycondensation, hydration of carbon monoxide, and selective liquid-phase oxidation of organics by peroxides. Anatase-phase titania has attracted extensive attention during the last few decades due to its excellent photocatalytic properties [23-25]. When $\mathrm{SiO}_{2}-\mathrm{TiO}_{2}$ composites are used as photocatalysts, titania is the more active component. However, titania alone has poor mechanical properties and a reduced specific surface area, its structural and sorption characteristics are less thermally stable, and titania suspensions are less stable with respect to coagulation. In some reactions, $\mathrm{SiO}_{2}$ $\mathrm{TiO}_{2}$ composites show even higher catalytic activity in comparison with $\mathrm{TiO}_{2}$ due to the higher concentration of catalytically active centers owing to the interaction between their components [26].

Taking into account those above presented, this paper is concerned with the generation of $\mathrm{TiO}_{2}$ $\mathrm{SiO}_{2}$ oxide mixtures using different ratios between the two components in a polydimethylsiloxane matrix according to an already reported solvent-free sol-gel procedure [27] The use of this alternative was imposed by the difficulty to find an efficient solvent for the whole system when this contains a relatively high molecular weight polysiloxane. In addition, the process we approached is economical and environmentally friendly because no solvents are required. The resulting materials were investigated for their morphology and tested as active elements in actuation devices.

\section{Experimental}

\subsection{Materials}

Polydimethylsiloxane- $\alpha, \omega$-diol, PDMS, $\quad\left(\overline{M_{\mathrm{v}}}=\right.$ $48000)$ was prepared according to a procedure described in previous papers [27, 28]. Tetraethylorthosilicate (TEOS) was purchased from Fluka (Steinheim, Germany). Tetrabutyl-orthotitanate (TBT) was purchased from Merck-Schuchardt (Hohenbrunn, Germany). Dibuthyltin dilaurate (DBTDL) was received from Merck-Schuchardt (Hohenbrunn, Germany). All of these materials were used as received.

Composites based on polydimethylsiloxane reinforced with silica and titania were prepared [27] by mixing polydimethylsiloxane with proper oxides precursors, TEOS and TBT, in different ratios, in the presence of DBTDL as a catalyst. PDMS was introduced in a Teflon dish and mixed with preestablished amounts of TEOS and TBT, according to Table 1. After $10 \mathrm{~min}$ of stirring, about $0.2 \mathrm{~g}$ of DBTDL was added and the stirring was continued for another $10 \mathrm{~min}$. The mixture was poured on a Teflon foil and vacuumed for $10 \mathrm{~min}$ to eliminate the incorporated air. The investigations were performed after the samples were kept in the laboratory for about 2 months. The tests revealed that this

Table 1. The recipes used to prepare $\mathrm{PDMS}-\mathrm{SiO}_{2}-\mathrm{TiO}_{2}$ composites [27]

\begin{tabular}{|l|c|c|c|c|}
\hline \multicolumn{1}{|c|}{ Sample } & \multicolumn{2}{|c|}{ Inorganic } & Organic & Catalyst \\
\hline & $\begin{array}{c}\text { TEOS } \\
{[\mathbf{w t} \% \text { \%] }}\end{array}$ & $\begin{array}{c}\text { TBT } \\
{[\mathbf{w t} \% \text { \%] }}\end{array}$ & $\begin{array}{c}\text { PDMS } \\
{[\text { wt.\%] }}\end{array}$ & $\begin{array}{c}\text { DBTDL } \\
{[\mathbf{w t} \%]}\end{array}$ \\
\hline T0 & 35.0 & 0.0 & 65 & 0.165 \\
\hline T5 & 32.5 & 2.5 & 65 & 0.196 \\
\hline T7.5 & 31.0 & 4.0 & 65 & 0.245 \\
\hline T10 & 30.0 & 5.0 & 65 & 0.222 \\
\hline T15 & 28.0 & 7.0 & 65 & 0.132 \\
\hline T20 & 26.0 & 9.0 & 65 & 0.166 \\
\hline Tr & 0.0 & 35.0 & 65 & 0.080 \\
\hline
\end{tabular}


period of time was sufficient to stabilize the mass of the samples.

\subsection{Equipments}

Crystallization and melting processes of PDMS based composites were followed using a Pyris Diamond DSC (Perkin Elmer USA) instrument. The samples were cooled from room temperature to $-150^{\circ} \mathrm{C}$, at a rate of $10^{\circ} \mathrm{C} / \mathrm{min}$, and then heated up to room temperature at a rate of $10^{\circ} \mathrm{C} / \mathrm{min}$. Helium was purged through the cells at a rate of $20 \mathrm{ml} / \mathrm{min}$ to insure an inert atmosphere and good thermal conductivity. Before the measurements, the instrument was calibrated for temperature and energy scales using $n$-hexane and pure water, according to the recommended standards for LN2 range of DSC analysis.

WAXD - Wide Angle X-rays Diffraction was performed on a Bruker-AXS D8 ADVANCE diffractometer, with Bragg-Brentano parafocusing goniometer. Scans were recorded in step mode using Ni-filtered $\mathrm{Cu} \mathrm{K} \mathrm{K}_{\alpha}$ radiation $(\lambda=0.1541 \mathrm{~nm})$. The working conditions were $40 \mathrm{kV}$ and $30 \mathrm{~mA}$ tube power. All diffractograms were collected in the range of $4-40^{\circ}, 2 \theta\left[^{\circ}\right]$, at $+24,-80,-110$ and $+24^{\circ} \mathrm{C}$. The cooling/heating rate (between isothermal registering data) was $20^{\circ} \mathrm{C} / \mathrm{min}$. A MRI-WRTC temperature chamber (with purged nitrogen atmosphere) and a MRI-TCPU1 temperature control power unit were used. The Bruker computer softwares Eva 11 and Topaz 3.1 were used to plot and process the data.

Microscopic investigation was performed on an Environmental Scanning Electron Microscope (ESEM) type Quanta 200 coupled with an Energy Dispersive of X-ray System. The SEM micrographs and corresponding EDX spectrum were recorded at $25 \mathrm{kV}$ with secondary electrons in low vacuum mode. The energy-dispersive X-ray system (EDX) coupled with the scanning electron microscope permitted to perform the elemental analysis on film surface.

The linear micro- and nano-displacements of polymeric membranes were determined using an experimental setup for linear measurements, based on a Michelson-type interferometer using an Agilent 5529A system. This interferometric system has a $2 \mathrm{~nm}$ resolution for linear displacement. The nano- actuation experiments were performed at a constant force of $22.5 \mathrm{cN}$.

\section{Results and discussion}

A series of polydimethylsiloxane-silica-titania composites with different mass ratios between organic and inorganic parts (Table 1) were prepared, processed as films, and subsequently investigated by different techniques. A polydimethylsiloxane- $\alpha, \omega$-diol was used as matrix for obtain composite materials with $\mathrm{SiO}_{2}$ and $\mathrm{TiO}_{2}$, by adapting a solvent-free sol-gel procedure already described [27]. TEOS and TBT oxide precursors were added in pre-established amounts to the polymer and DBTDL was added as catalyst. After vigorous stirring of the reactants and removing of the formed gas, the obtained mixtures were processed as films. The hydrolysis of the corresponding precursors took place under the influence of atmospheric humidity and it was followed by catalytic condensation with the formation of silicon and titanium oxides networks [29], several days being required to complete the process. As a result of the reactions between the alkoxydes and their hydrolysates with $\mathrm{Si}-\mathrm{OH}$ PDMS end groups, the crosslinking of PDMS occurred. White opaque films (of about $0.2-$ $0.9 \mathrm{~mm}$ thickness), easily detachable (peeled) from the substrate were obtained. The sum of $\mathrm{SiO}_{2}$ and $\mathrm{TiO}_{2}$ is considered as the inorganic part, while PDMS is considered to represent the organic part of the composites. The $\mathrm{SiO}_{2} / \mathrm{TiO}_{2}$ ratio was varied, but their cumulated amounts remained constant, as previously reported by other authors [30].

\subsection{Differential scanning calorimetry}

Different from the procedure previously reported [27], the present approach consisted of cooling and heating the samples at a controlled rate of $10^{\circ} \mathrm{C} / \mathrm{min}$. As a consequence, the transitions are better evidenced and can be correlated with the XRD data also obtained under controlled heatingcooling conditions (Figure 1). Both cooling and heating curves shown slight changes in both melting and crystallization processes depending on the filler content. The main data of the DSC curves $\left(T_{\text {peak }}, \Delta H\right)$ are summarized in Table 2. For all compositions, it can be observed that, while the peak temperatures $\left(T_{\mathrm{c}}, T_{\mathrm{m}}\right)$ remain almost constant (max- 

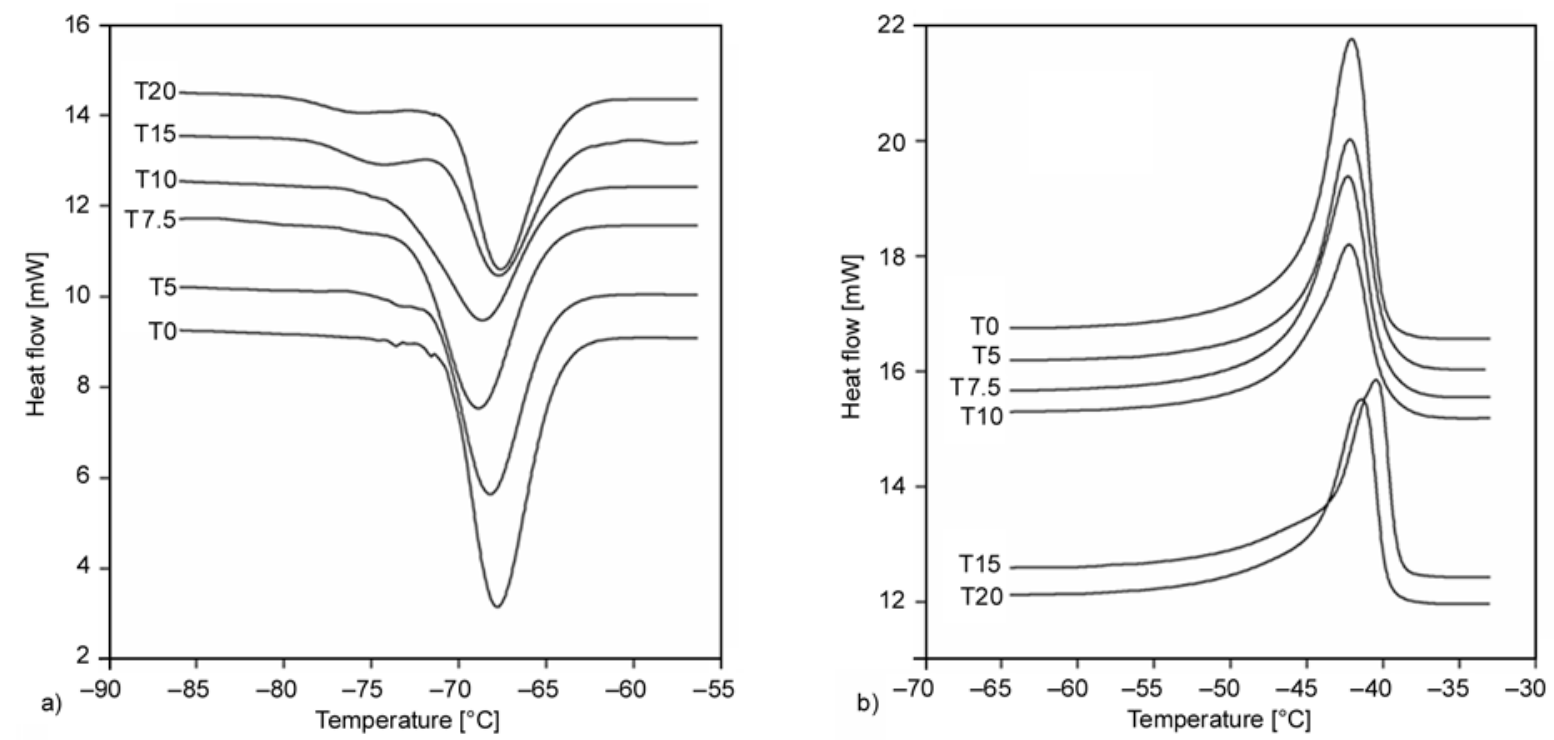

Figure 1. Crystallization processes (a) and melting endotherms (b) in $\mathrm{PDMS} / \mathrm{SiO}_{2} / \mathrm{TiO}_{2}$ composites

imum 1 degree), the enthalpy is affected, its values lowering in the presence of the titania. The nucleation processes occurring on cooling are restricted by the presence of fillers, so the decreasing of crystallization enthalpy is related to the development of a less crystalline fraction within the matrix. In the heating curves, this behavior is also observed by the decrease of the melting enthalpy of samples due to a less crystalline phase developed in the cooling process. The presence of $\mathrm{TiO}_{2}$ limits the quantity of crystals developed in the PDMS matrix.

The XRD diffractograms (Figures 2 and 3), reveal that the crystals have the same organization (peaks $\mathrm{XRD}$ ), which can be related to same values for $T_{\mathrm{c}}$ or

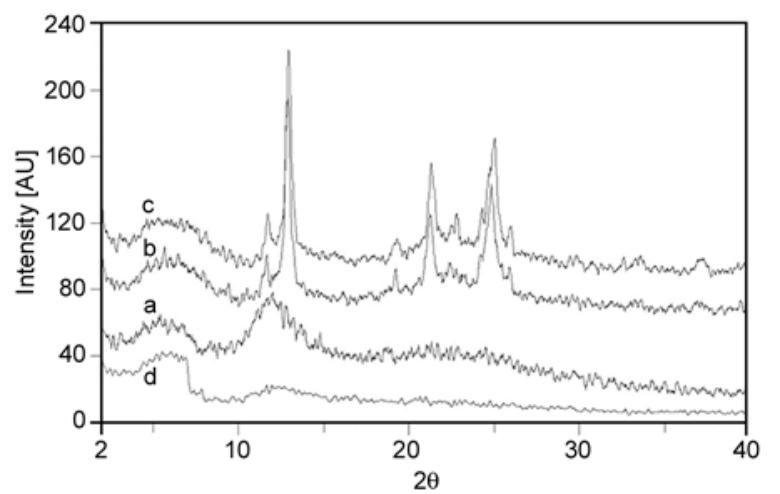

Figure 2. Diffractograms of sample $\mathrm{T} 7.5$ at a) $+24^{\circ} \mathrm{C}$, b) $\left.\left.-80^{\circ} \mathrm{C}, \mathrm{c}\right)-110^{\circ} \mathrm{C}, \mathrm{d}\right)+24^{\circ} \mathrm{C}$
$T_{\mathrm{m}}$ for all the components. In order to estimate the $\Delta H_{\mathrm{c}}$ value, we considered that the crystallization process is completed after the lower exotherm appeared as a shoulder on the curves corresponding to the samples containing more than $10 \%$ titania. It is possible that a higher $\mathrm{TiO}_{2}$ content, can lead to the development of a separate morphology. However, a more elaborate study is needed to test this hypothesis but this is not the aim of this study.

\subsection{WAXD - wide angle $X$-Rays diffraction}

Crystallisable polymers tend to develop a certain level of crystallinity when heated above glass transition temperature. Semicrystalline polymers typi-

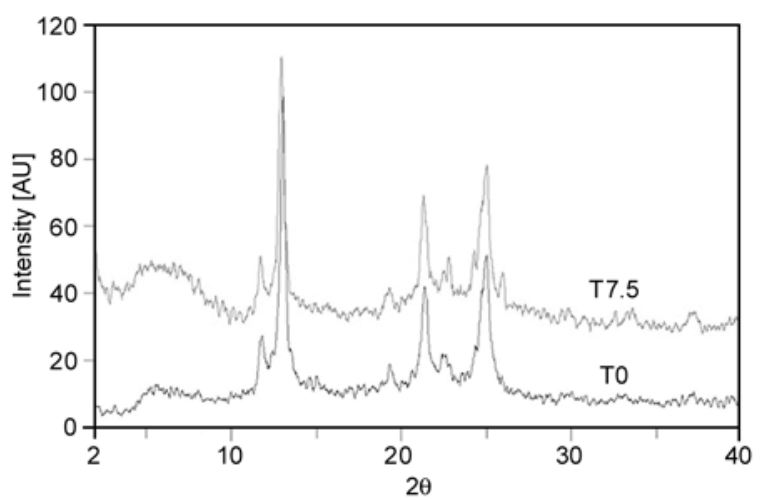

Figure 3. Diffractograms of samples T0 and T7.5 registered at $-110^{\circ} \mathrm{C}$

Table 2. Cooling and heating enthalpies normalized in relation to PDMS amount for the composites

\begin{tabular}{|l|l|c|c|c|c|c|c|}
\hline \multicolumn{2}{|c|}{ Sample } & T0 & T5 & T7.5 & T10 & T15 & T20 \\
\hline$\Delta H_{\text {norm }}[\mathrm{J} / \mathrm{g}]$ & \multirow{2}{*}{ Cooling } & -16.50 & -13.40 & -13.95 & -12.00 & -11.34 & -12.23 \\
\cline { 3 - 8 }$T_{\text {peak }}$ & & -67.80 & -68.24 & -68.89 & -68.63 & -67.75 & -67.58 \\
\hline$\Delta H_{\text {norm }}[\mathrm{J} / \mathrm{g}]$ & \multirow{2}{*}{ Heating } & -16.57 & -13.50 & -13.32 & -11.04 & -11.85 & -11.45 \\
\cline { 3 - 9 }$T_{\text {peak }}$ & & -42.04 & -42.18 & -42.28 & -42.24 & -40.45 & -41.42 \\
\hline
\end{tabular}


cally show a distinct lamellar morphology consisting of stacks of laminar crystals intercalated by amorphous, less ordered regions. Taking into account the DSC data, for the studied materials the crystallization can occur, at least for a fraction of the polymer, when slow cooling below $-40{ }^{\circ} \mathrm{C}$ takes place. However, the cooling rate should be low enough to allow chains to form crystalline structures.
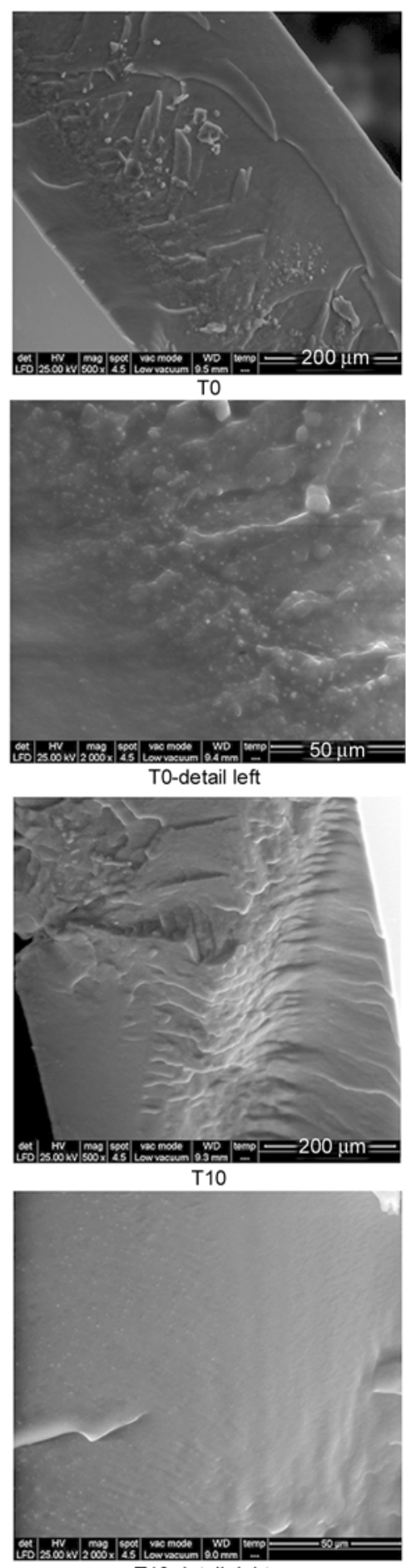

T10-detail right

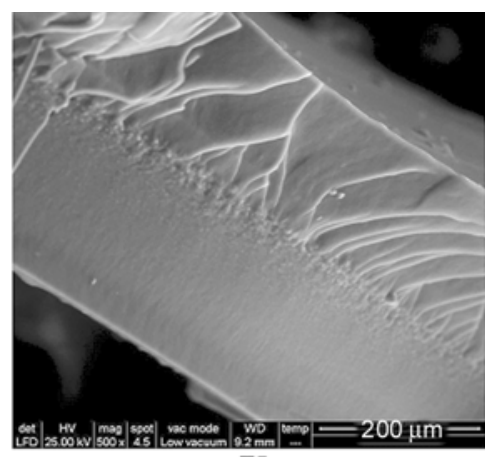

T5

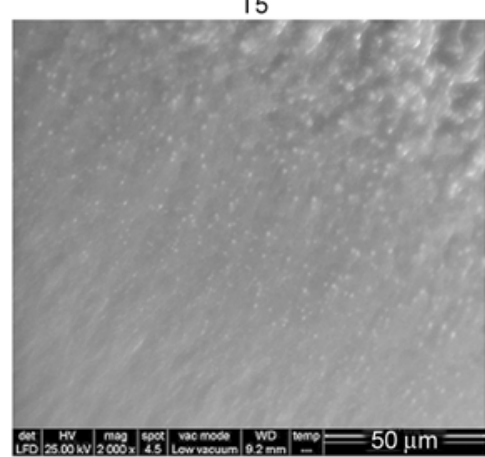

T5-detail left

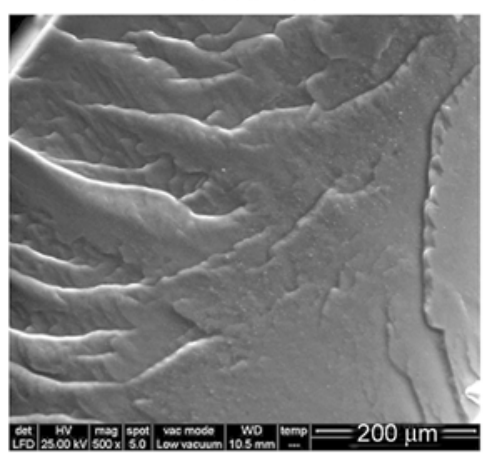

T15

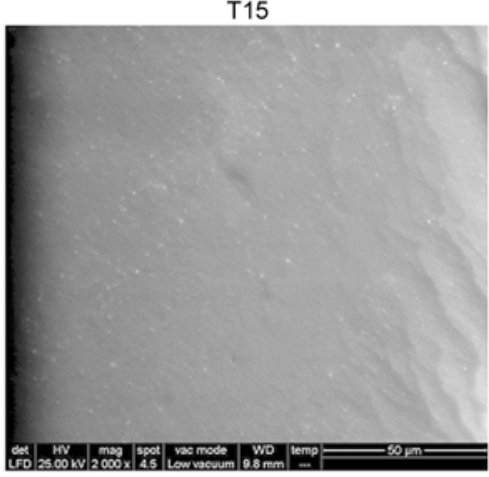

T15-detail right
The X-ray diffractograms registered at different temperatures $\left(+24,-80,-110,+24^{\circ} \mathrm{C}\right)$ show an amorphous state at room temperature both initially and after a cooling-heating cycle for all used $\mathrm{SiO}_{2} /$ $\mathrm{TiO}_{2}$ ratios. On the other hand, when cooling the samples at -80 and $-110^{\circ} \mathrm{C}$ all composites show a high crystallization degree (Figure 2). This behavior is due to the cold crystallization process that, according to DSC data, takes place around $-68^{\circ} \mathrm{C}$.
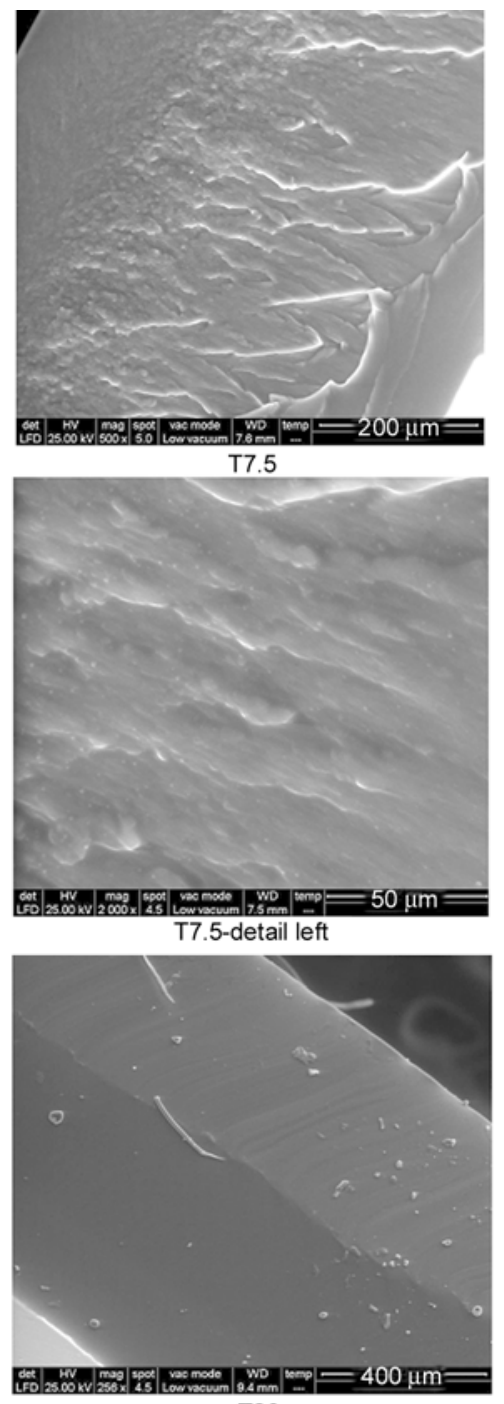

T20

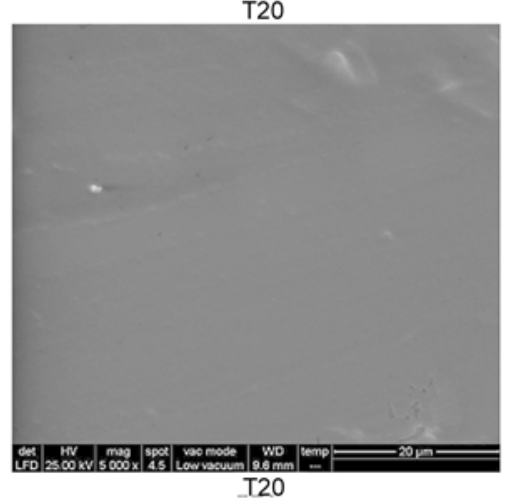

Figure 4. SEM micrographs of the broken surfaces deposed on Al supports and coated with Au 
Because the crystallization seems to end at $-75^{\circ} \mathrm{C}$, the diffractograms at -80 and $-110^{\circ} \mathrm{C}$ show almost the same pattern (Figure 2b, 2c). At room temperature, the samples are above the melting point of the polymeric chains (about $-40^{\circ} \mathrm{C}$ ) showing as a result an amorphous state.

At first glance, at a certain temperature the samples show similar diffractogram patterns regardless the composition, suggesting that the morphology is dictated mainly by the polydimethylsiloxane matrix. A comparison between the diffractograms of the samples $\mathrm{T} 0$ and $\mathrm{T} 7.5$ at $-110^{\circ} \mathrm{C}$ is provided as an example in Figure 3.

However, a deeper analysis of the diffractograms registered for different samples at the same temperature allows the observation of a decrease in the degree of crystallinity in the composite with the increase of $\mathrm{TiO}_{2}$ content. It is to presume that $\mathrm{TiO}_{2}$, structurally different from PDMS, acts as a disruptive agent during the crystallization of the polymeric chains. At the same time, the amount of titania is low and doesn't meet the conditions to develop and impose its own ordering.

\subsection{Scanning electron microscopy}

SEM micrographs of the cross section of the prepared film composites are displayed in Figure 4. A globular texture concentrated toward the center section can be observed, while the outward surface appears to be smooth. The natural tendency of polydimethylsiloxane chains to migrate to the surface determines this stratification phenomenon. As globular domains can be seen in the sample T0 without titania, these are attributed to the silica. With increasing titania content, these domains become scarce and the surface becomes smoother, and in the case of sample T20 which has the lowest silica content, the globular domains are almost absent.

The EDX analyses, performed to identify the nature of the atoms present in the samples at a depth of $100-1000 \mathrm{~nm}$ from the surface, proved the presence of all expected elements (C, O, Si, and Ti) (Figure 5).

The well-known tendency of segregation to the surface of polysiloxane confer hydrophobicity as well as very low porosity (BET surface: $6.6-17 \mathrm{~m}^{2} / \mathrm{g}$ ) [27] which make such composites not suitable for photocatalysis. In this respect, our attempts aimed to decompose Bromothymol blue in aqueous solu-
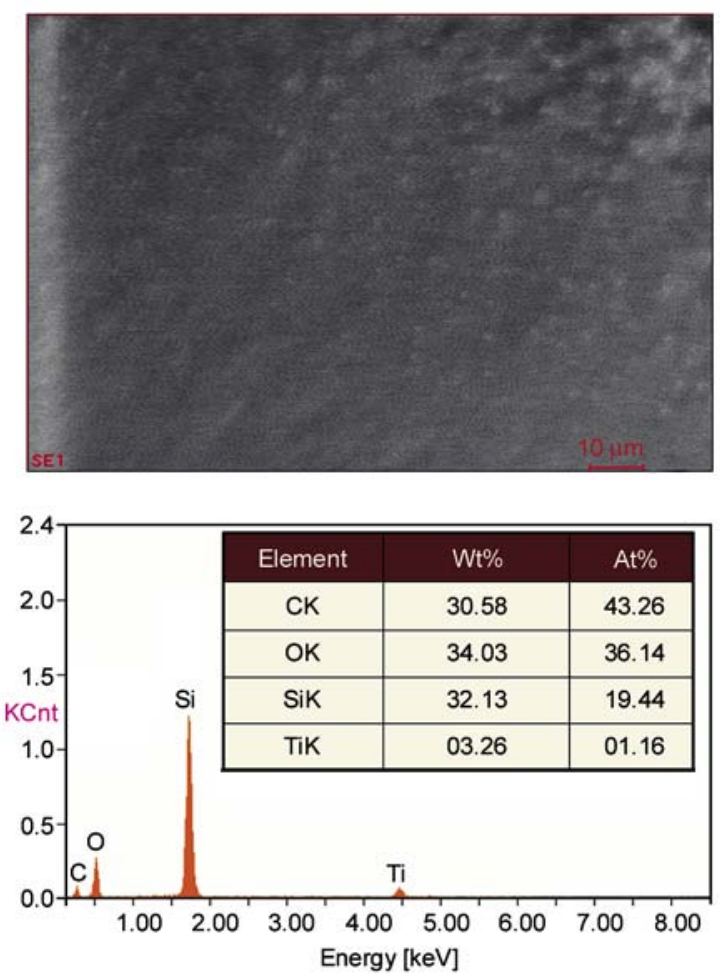

Figure 5. EDX analysis of T5 composite

tion failed. Thus, the UV spectrum of a solution containing $0.0048 \mathrm{wt} . \%$ bromothymol blue in water remained unmodified after immersion of a piece of composite film sample and irradiation for different time periods with an UV lamp of $250 \mathrm{~W}$.

\subsection{Nano-actuation measurements}

Due to their interesting properties such as elasticity, insulating ability and easy processing, silicones are used in microelectromechanical systems (MEMS) where they play a structural role as protective layers, encapsulating elements, valves and diaphragms. However, by using active fillers, the dielectric properties of silicones can be modified [21, 22]. Films containing $\mathrm{TiO}_{2}$ have been often used in microelectronic devices, e.g. in capacitors, or as a dielectric gate in metal-dielectric-semiconductor devices [19]. The composites processed as films have been tested for actuation effect. The microelectromechanical actuation experiments have been performed by using the Agilent 5529A interferometric method. The measurements of the film nano-displacements were carried out using the time operation module of the Agilent system that can determine the position, velocity and acceleration as a function of time. For this, a voltage was applied by using thin electrodes that ensure a good electric contact with the polymer 

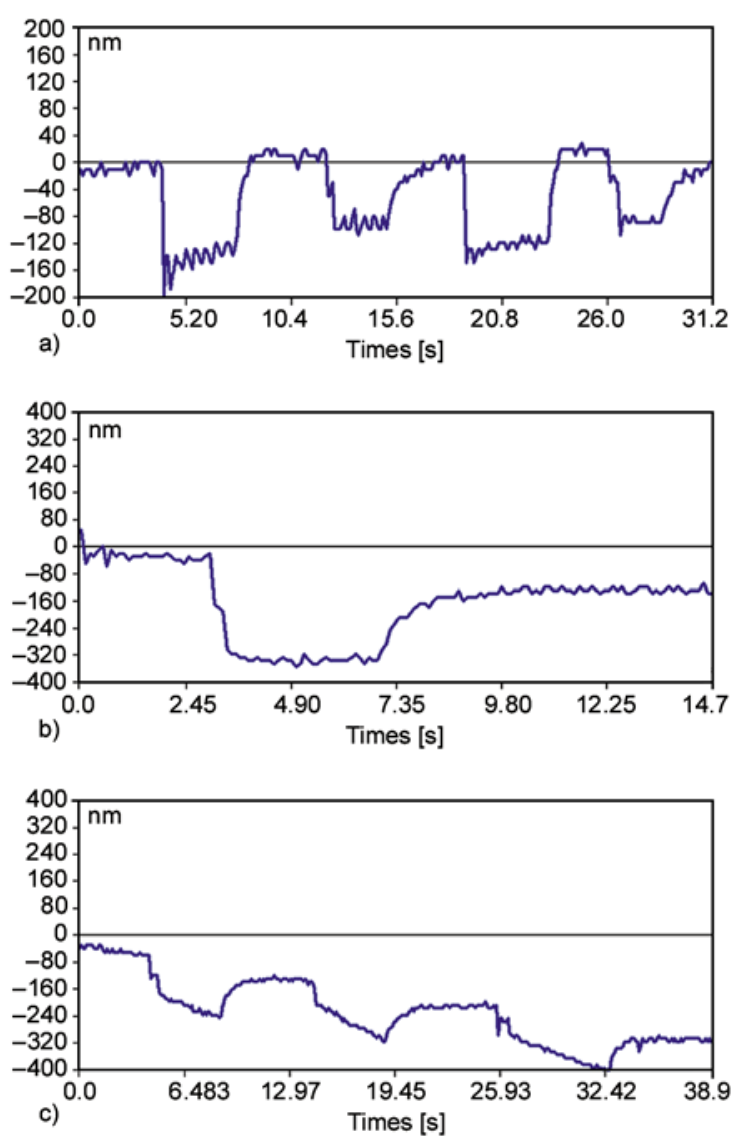

Figure 6. Nanometric displacements of the composite films at $400 \mathrm{~V}$ : a) T10; b) T20; c) Tr

film and good mechanical roughness at the contact with the retroreflector. The experiments were performed using a manual switch to control the continuum electric field (DC). The signals shown in Figure 6 represent the film actuation responses to a DC electric field.

Nano-electromechanical noise appears due to the dielectric membrane effects. The local dielectric parameters (conductivity, permittivity and dielectric loss angle) are changed in the electric field, this effect causing an unstable response. It is considered that the nano-actuation has an electrostriction character. The mechanical forces arising in a dielectric, in this case the polymeric composite film, under the action of an electric field tend to deform the membrane [31].

The specific actuation parameters of the experiments performed on polymer composites films are summarized in Table 3.

A previous study [27] reported that by incorporating $\mathrm{TiO}_{2}$ in a PDMS-silica matrix the dielectric con-
Table 3. Actuation parameters

\begin{tabular}{|l|c|c|c|}
\hline Sample & $\begin{array}{c}\text { Voltage } \\
\mathbf{U}[\mathbf{V}]\end{array}$ & $\begin{array}{c}\text { Maximum displacement } \\
\text { (actuation) } \\
\mathbf{d}[\mathbf{n m}]\end{array}$ & $\begin{array}{c}\text { Actuation } \\
\text { sensitivity } \\
\mathbf{S}\left[\mathbf{n m} \cdot \mathbf{V}^{-\mathbf{1}} \text { ] }\right.\end{array}$ \\
\hline $\mathrm{T} 10$ & 400 & 180 & 0.45 \\
\hline $\mathrm{T} 20$ & 400 & 360 & 0.90 \\
\hline $\mathrm{Tr}$ & 400 & 400 & 1.00 \\
\hline
\end{tabular}

stant increases by several units, which would be a prerequisite for improving the actuation properties, taking into account the silicone's low modulus and low flexibility. Indeed, the samples proved to be able for actuation, a better behavior being observed for sample Tr, which contains a high percent of $\mathrm{TiO}_{2}$ (without silica): $400 \mathrm{~nm}$ displacement at $400 \mathrm{~V}$ (Figure 6). The sensitivity values $S$ (the ratio between maximum displacement and the applied voltage) - a significant parameter for actuation also increase by rising titania content in the material in the order $\mathrm{T} 10<\mathrm{T} 20<\mathrm{Tr}$ (Table 2), the sample Tr containing about $35 \%$ titania.

\section{Conclusions}

A series of composites have been prepared by partial replacement of $\mathrm{SiO}_{2}$ in a PDMS-silica composite with $\mathrm{TiO}_{2}$ (both generated in-situ by a sol-gel process). The introduction of titania proved to have the following effects: crystallization and melting temperatures values changed as compared to the blank sample, while the crystallization degree slightly decreased as titania content increased. The tendency to form particles agglomeration on the surface is reduced as silica is partially replaced with titania in the composite. The prepared composites showed good values for the main parameters in microelectromechanical actuation tests (displacement, sensitivity, and response time), which recommends them for planar or multilayer actuators. This behavior improves with increasing the titanium dioxide content.

\section{Acknowledgements}

This work was financially supported by Project PN II-PC 12-128/2008 (ELOTRANSP).

\section{References}

[1] Ames J.: Silicones and their applications. Journal of Scientific Instruments, 35, 1-7 (1958). DOI: $\underline{10.1088 / 0950-7671 / 35 / 1 / 302}$ 
[2] Dollase T., Spiess H. W., Gottlieb M., YerushalmiRozen R.: Crystallization of PDMS: The effect of physical and chemical crosslinks. Europhysics Letters, 60, 390-396 (2002).

DOI: 10.1209/epl/i2002-00276-4

[3] Yamada N., Yoshinaga I., Katayama S.: Formation behavior and optical properties of transparent inorganic-organic hybrids prepared from metal alkoxides and polydimethylsiloxane. Journal of Sol-Gel Science and Technology, 17, 123-130 (2000).

DOI: 10.1023/A:1008787200364

[4] Rojas-Cervantes M. L., López-Peinado A. J., MartínAranda R. M., Gómez-Serrano V.: Synthesis and characterisation of $x \mathrm{TiO} 2 \cdot(1-x) \mathrm{SiO}_{2}-$ carbon composites. Carbon, 41, 79-86 (2003).

DOI: 10.1016/S0008-6223(02)00273-7

[5] Pẽna-Alonso R., Téllez L., Rubio J., Rubio F.: Surface chemical and physical properties of TEOS-TBOTPDMS hybrid materials. Journal of Sol-Gel Science and Technology, 38, 133-145 (2006).

DOI: $10.1007 / \mathrm{s} 10971-006-7116-6$

[6] Akinci A.: Mechanical and morphological properties of basalt filled polymer matrix composites. Archives of Materials Science and Engineering, 35, 29-32 (2009).

[7] Wang X. X., Wang H. T., Song X. M., Wang G. Q., Du Q. G., Chen Q. T.: Photocatalytic polymerization induced by a transparent anatase titania aqueous sol and fabrication of polymer composites. Express Polymer Letters, 4, 373-381 (2010).

DOI: $10.3144 /$ expresspolymlett.2010.47

[8] Monson T. C., Huber D. L: High refractive index $\mathrm{TiO}_{2}$ nanoparticle silicone composites. in 'Physical, chemical, and nano sciences center research briefs 2008' Sandia National Laboratories Albuquerque (2008).

[9] Mirabedini S. M., Mohseni M., PazokiFard Sh., Esfandeh M.: Effect of $\mathrm{TiO}_{2}$ on the mechanical and adhesion properties of RTV silicone elastomer coatings. Colloids and Surfaces A: Physicochemical and Engineering Aspects, 317, 80-86 (2008).

DOI: $10.1016 /$ j.colsurfa.2007.09.044

[10] Chen Y., Lin A., Gan F.: Improvement of polyacrylate coating by filling modified nano- $\mathrm{TiO}_{2}$. Applied Surface Science, 252, 8635-8640 (2006).

DOI: $10.1016 /$ j.apsusc.2005.11.083

[11] Yang M., Dan Y.: Preparation and characterization of poly(methyl methacrylate)/titanium oxide composite particles. Colloid and Polymer Science, 284, 243-250 (2005).

DOI: $10.1007 / \mathrm{s} 00396-005-1356-8$

[12] Zhu M., Xing Q., He H., Zhang Y., Chen Y., Pötschke P., Adler H-J.: Preparation of PA6/nano titanium dioxide $\left(\mathrm{TiO}_{2}\right)$ composites and their spinnability. Macromolecular Symposia, 210, 251-261 (2004).

DOI: $10.1002 /$ masy.200450629
[13] Tsai M-H., Liu S-J., Chiang P-C.: Synthesis and characteristics of polyimide/titania nano hybrid films. Thin Solid Films, 515, 1126-1131 (2006).

DOI: $10.1016 / j . t s f .2006 .07 .092$

[14] Rong Y., Chen H-Z., Li H-Y., Wang M.: Encapsulation of titanium dioxide particles by polystyrene via radical polymerization. Colloids and Surfaces A: Physicochemical and Engineering Aspects, 253, 193-197 (2005).

DOI: $10.1016 /$ j.colsurfa.2004.11.018

[15] Hwang D. K., Moon J. H., Shul Y. G., Jung K. T., Lim D. H., Lee D. W.: Scratch resistant and transparent UV-protective coating on polycarbonate. Journal of Sol-Gel Science and Technology, 26, 783-787 (2003). DOI: $10.1023 / \mathrm{A}: 1020774927773$

[16] Wetzel B., Rosso P., Haupert F., Friedrich K.: Epoxy nanocomposites- Fracture and toughening mechanisms. Engineering Fracture Mechanics, 73, 23752398 (2006).

DOI: 10.1016/j.engfracmech.2006.05.018

[17] Xiao Y., Wang X., Yang X., Lu L.: Nanometre-sized $\mathrm{TiO}_{2}$ as applied to the modification of unsaturated polyester resin. Materials Chemistry and Physics, 77, 609-611 (2002).

DOI: $10.1016 / \mathrm{S} 0254-0584(02) 00114-1$

[18] Yoshida K., Tanagawa M., Atsuta M.: Effects of filler composition and surface treatment on the characteristics of opaque resin composites. Journal of Biomedical Materials Research Part B: Applied Biomaterials, 58, 525-530 (2001).

DOI: $10.1002 / \mathrm{jbm} .1050$

[19] Răileanu M., Crişan M., Drăgan N., Crişan D., Galtayries A., Brăileanu A., Ianculescu A., Teodorescu V. S., Niţoi I., Anastasescu M.: Sol-gel doped $\mathrm{TiO}_{2}$ nanomaterials: A comparative study. Journal of Sol-Gel Science and Technology, 51, 315-329 (2009).

DOI: $10.1007 / \mathrm{s} 10971-009-2017-\mathrm{z}$

[20] Bokobza L., Diop A. L.: Reinforcement of poly (dimethylsiloxane) by sol-gel in situ generated silica and titania particles. Express Polymer Letters, 4, 355363 (2010).

DOI: $10.3144 /$ expresspolymlett.2010.45

[21] Cazacu M., Ignat M., Racles C., Vlad A., Alexandru M., Zarnescu G.: Polydimethylsiloxane/silica composites incorporating pyrite powders for actuation elements. Polymer International, 58, 745-751 (2009). DOI: $10.1002 /$ pi.2586

[22] Cazacu M., Ignat M., Vlad A., Alexandru M., Zarnescu G.: Heat-cured silicone rubber incorporating pyrite powders for actuation elements. Optoelectronics Advanced Materials Rapid Communication, 4, 349351 (2010). 
[23] Yu J-G., Yu H-G., Cheng B., Zhao X-J., Yu J. C., Ho W-K.: The effect of calcinations temperature on the surface microstructure and photocatalytic activity of $\mathrm{TiO}_{2}$ thin films prepared by liquid phase deposition. Journal of Physical Chemistry B, 107, 13871-13879 (2003). DOI: 10.1021/jp036158y

[24] Petkowicz D. I., Pergher S. B. C., Silva da Silva C. D., da Rocha Z. N., dos Santos J. H. Z.: Catalytic photodegradation of dyes by in situ zeolite-supported titania. Chemical Engineering Journal, 158, 505-512 (2010). DOI: 10.1016/j.cej.2010.01.039

[25] Alem A., Sarpoolaky H., Keshmiri M.: Sol-gel preparation of titania multilayer membrane for photocatalytic applications. Ceramics International, 35, $1837-$ 1843 (2009).

DOI: 10.1016/j.ceramint.2008.10.034

[26] Murashkevich A. N., Lavitskaya A. S., Alisienok O. A. Zharskii I. M.: Fabrication and properties of $\mathrm{SiO}_{2} /$ $\mathrm{TiO}_{2}$ composites. Inorganic Materials, 45, 1146-1152 (2009).

DOI: $10.1134 / \mathrm{S} 0020168509100124$
[27] Alexandru M., Cazacu M., Nistor A., Musteata V. E., Stoica I., Grigoras C., Simionescu B. C.: Polydimethylsiloxane/silica/titania composites prepared by solventfree sol-gel technique. Journal of Sol-Gel Science and Technology, 56, 310-319 (2010). DOI: $10.1007 / \mathrm{s} 10971-010-2307-5$

[28] Cazacu M., Marcu M.: Silicone rubbers IX. Contributions to polydimethylsiloxane- $\alpha, \omega$-diols synthesis by heterogeneous catalysis. Journal of Macromolecular Science Part A: Pure and Applied Chemistry, 32, 1019-1029 (1995). DOI: $10.1080 / 10601329508019142$

[29] Rubio F., Rubio J., Oteo J. L.: Effect of $\mathrm{TiO}_{2}$ on the pore structure of $\mathrm{SiO}_{2}$-PDMS ormosils. Journal of SolGel Science and Technology, 18, 105-113 (2000). DOI: 10.1023/A:1008704701204

[30] Diré S., Babonneau F., Sanchez C., Livage J.: Sol-gel synthesis of siloxane-oxide hybrid coatings $\left[\mathrm{Si}\left(\mathrm{CH}_{3}\right)_{2} \mathrm{O} \cdot \mathrm{MO}_{\mathrm{x}}: \mathrm{M}=\mathrm{Si}, \mathrm{Ti}, \mathrm{Zr}, \mathrm{Al}\right]$ with luminescent properties. Journal of Materials Chemistry, 2, 239-244 (1992).

DOI: $10.1039 / J M 9920200239$

[31] Tareev B.: Physics of dielectric materials. Mir Publishers, Moscow (1975). 